\section{DISCUSSION}

Although several surgical options have been widely established in the treatment of renal cell carcinoma extending into the IVC, whenever a potential involvement of the right atrium is suspected, the use of cardiopulmonary bypass with hypothermic arrest is usually adopted, albeit such technique yields potential risks, mainly in terms of coagulopathy. ${ }^{4}$

Because the huge dimensions and extension close to the right atrium of the neoplastic thrombus could have made its removal potentially cumbersome and therefore significantly prolonged the duration of hypothermic circulatory arrest, a novel perfusion strategy was adopted to allow continuous perfusion of the supra-aortic vessels during systemic circulatory arrest. Therefore, as described in the present report, the cardiopulmonary bypass temperature can be maintained at a greater degree than conventional hypothermic circulatory arrest $\left(\sim 18^{\circ} \mathrm{C}\right)$. Moreover, the described modification is cost-effective, without consistent modifications to the cardiopulmonary bypass circuit.

\section{CONCLUSIONS}

Although further clinical experience is warranted to confirm the encouraging results of our preliminary case, we believe this simple modification could represent a useful tool that adds to the surgical armamentarium for the treatment of renal cell carcinoma with intra-atrial thrombus.

\section{References}

1. Novick AC, Cosgrove DM. Surgical approach for removal of renal cell carcinoma extending into the vena cava and the right atrium. J Urol. 1980;123:947-50.

2. Paul JG, Rhodes MB, Skow JR. Renal cell carcinoma presenting as right atrial tumor with successful removal using cardiopulmonary bypass. Ann Surg. 1975;181:471-3.

3. Vaidya A, Ciancio G, Soloway M. Surgical techniques for treating a renal neoplasm invading the inferior vena cava. J Urol. 2003;169:435-44.

4. Harrington DK, Fragomeni F, Bonser RS. Cerebral perfusion. Ann Thorac Surg. 2007;83:S799-804.

\title{
Latero-lateral slide tracheoplasty for upper airway stenosis: An 8-year follow-up
}

\author{
Erdal Tasci, MD, ${ }^{\mathrm{a}}$ Halil Ciftci, MD, ${ }^{\mathrm{a}}$ Farzin Periovi, MD, ${ }^{\mathrm{b}}$ and Cemal Asim Kutlu, MD, FETCS, ${ }^{\mathrm{a}}$ Istanbul, Turkey
}

Since slide tracheoplasty (ST) was defined in $1989,{ }^{1}$ the scope of the technique has been further extended, as evidenced by reported cases of satisfactory outcomes. ST has been used for almost all types of long-segment tracheal stenosis, including "bilateral main bronchus stenosis", and "congenital laryngeal atresia (slide thyrocricotracheoplasty).,"3 We slightly modified the original technique and performed latero-lateral ST in a patient who presented with an acquired long-segmental stenosis. We report the patients' long-term follow-up.

\section{CLINICAL SUMMARY}

A 46-year-old man presented with a long-segment stenosis involving the subglottic area and proximal trachea caused by tracheobronchopathia osteochondroplastica. Spirometry showed a forced expiratory volume in 1 second of $1.46 \mathrm{~L}$ $(43 \%$ predicted) and a forced vital capacity of $3.06 \mathrm{~L}$

From the Department of Thoracic Surgery, Sureyyapasa Chest Diseases and Chest Surgery Teaching and Research Hospital, ${ }^{\mathrm{a}}$ Istanbul, Turkey; and Medica Imaging Centre, ${ }^{\mathrm{b}}$ Istanbul, Turkey.

Received for publication Feb 5, 2008; accepted for publication March 20, 2008.

Address for reprints: Cemal Asim Kutlu, MD, FETCS, Medkon, Hakki Yeten Cad. 12/

12, Şisli 34394, Istanbul, Turkey (E-mail: cakutlu@tnn.net).

J Thorac Cardiovasc Surg 2009;137:e44-6

$0022-5223 / \$ 36.00$

Copyright (c) 2009 by The American Association for Thoracic Surgery doi:10.1016/j.jtcvs.2008.03.041
( $81 \%$ predicted). Bronchoscopy relieved that the stenosis involved the subglottic area and proximal half of the trachea. Modified ST was undertaken via median sternotomy, and the anterior surface of the trachea was exposed to adjust the oblique (right to left) and longitudinal tracheal cuts along the stenosis. The longitudinal cut on the lateral surface of the proximal tracheal segment was extended superiorly up to the thyroid cartilage; the distal segment was then slid up after trimming both margins. Contrary to our routine technique for anastomosis, the cartilaginous part of the trachea was anastomosed with polyglycolic acid using an interrupted suture technique because of the thick and calcified tracheal wall.

Postoperatively, the main concern was the suture line healing in the oldest patient undergoing ST among the reported patients. Bronchoscopy was performed 2 times for bronchial toilet in the early postoperative course. This case was reported 15 months after the surgery when the patient had resumed his normal life without any respiratory problems or restrictions in his daily activities. ${ }^{4}$ Since then, he has not required any hospitalization, and chest x-rays taken by his primary physician showed no abnormality. $\mathrm{He}$ did not receive any medication, including bronchodilators and steroids. We invited him to our outpatient clinic 8 years after the operation to investigate the long-term results of the operation. On examination, no abnormality 


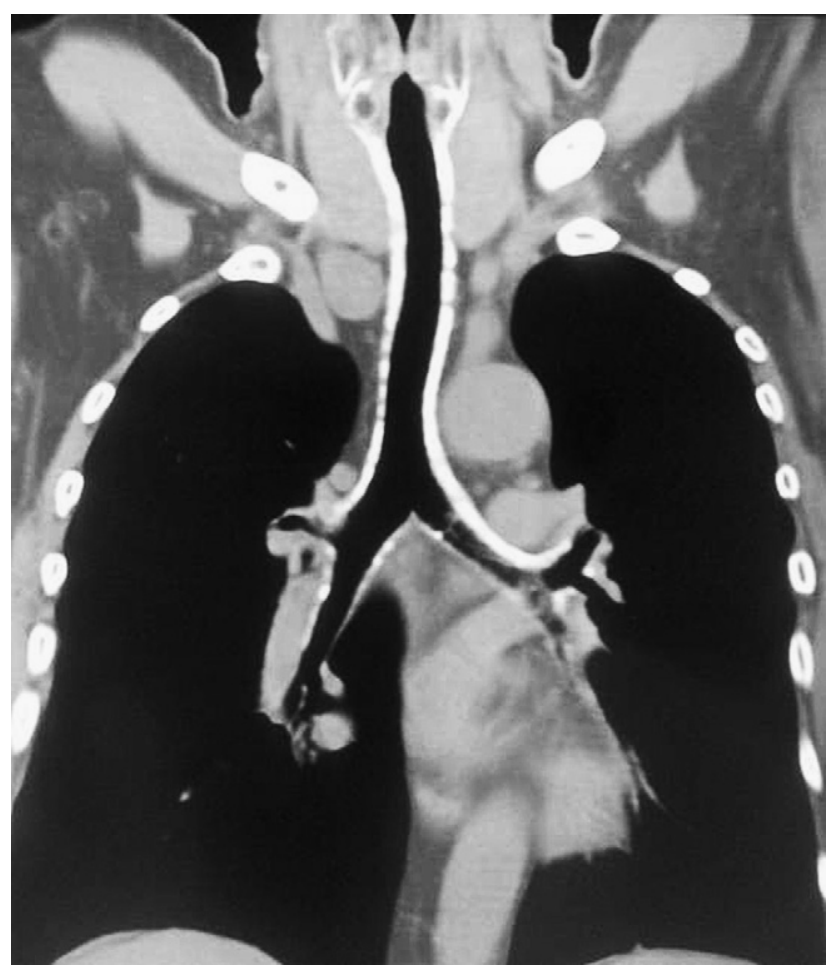

FIGURE 1. Tracheal lumen 8 years after latero-lateral ST.

was detected; breath sounds were within normal limits. Spirometry showed a forced expiratory volume in 1 second of $1.91 \mathrm{~L}(69 \%$ predicted) and a forced vital capacity of 2.6 L (74\% predicted). A computed tomography scan revealed no stricture in the lumen (Figure 1), and the tracheal cartilages were clearly seen at the inferior part of the thyroid cartilage on the left side (Figure 2). In regard to clinical and radiologic findings, bronchoscopy for only academic purposes seems inappropriate to perform.

\section{DISCUSSION}

A 2-fold increase in the number of capillary vessels in newborn trachea may explain the low rate of ischemic complications after ST despite extensive mobilization and long suture lines. Despite the satisfactory outcome in the long term, ${ }^{5}$ ST has yet to be confirmed for the management of acquired tracheal stenosis. Furthermore, ST has been performed in babies and young adults. Therefore, for our middle-aged patient, we modified the original technique by dividing the trachea from the right to the left to preserve the lateral longitudinal tracheal vessels, which are unavoidably damaged in the original technique. Our modification allows preserving the tracheal vessels on one side, which supply the entire tracheal segment through the anterior anastomosis.

This modification also enables widening of the proximal part of the stenosis involving the subglottic area ${ }^{4}$

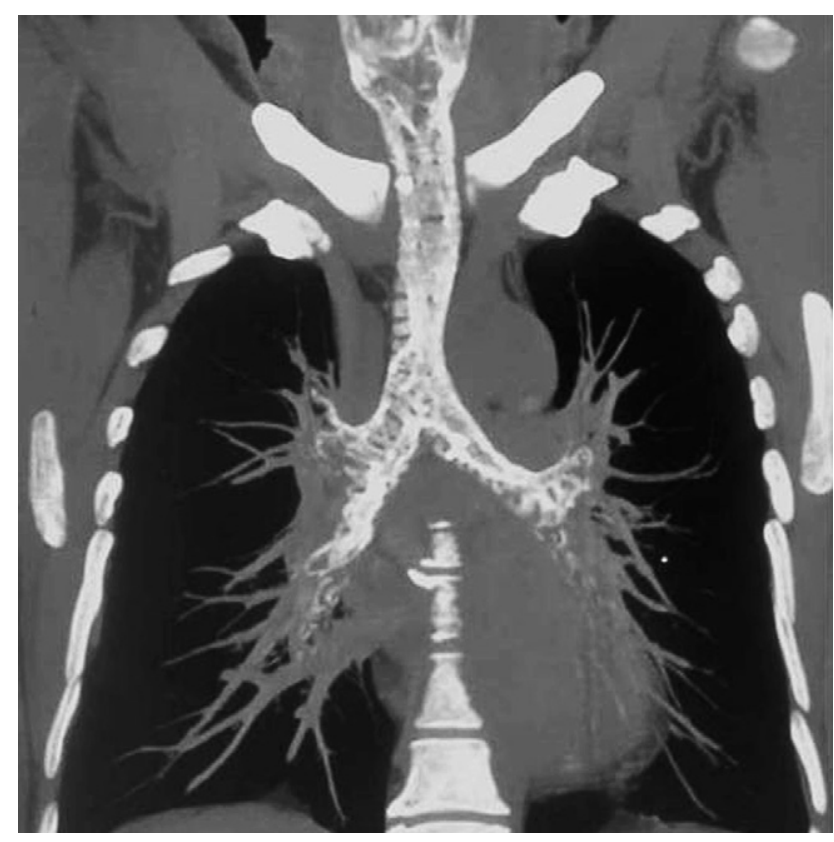

FIGURE 2. Appearance of the trachea on control computed tomography scan. On the left, the tip of the distal tracheal segment that slid up to the thyroid cartridge is seen.

by sliding the tip of the distal segment to the inferior edge of the thyroid cartridge. The outcome of our case suggests that ST may be undertaken not only for acquired stenosis but also for subglottic stenosis. Kim and colleagues ${ }^{3}$ recently extended the limits of the original technique and adopted a similar approach in a 7-month-old baby who presented with a congenital laryngeal atresia. In their technique, the lower third of the thyroid cartilage and cricoid was dissected and the tip of the distal tracheal segment was slid anteriorly to widen the laryngotracheal stenosis. The postoperative course was uneventful, and 18 months after the operation, satisfactory outcome was reported.

\section{CONCLUSIONS}

This result confirms our observation that ST may be considered for the management of proximal airway stenosis involving the subglottic area. The satisfactory long-term outcome of the latero-lateral modification suggests that ST may be a reasonable option for an acquired long segmental tracheal stenosis. Despite the hypothetic advantages, the beneficial effect of our modification remains to be confirmed.

\section{References}

1. Tsang V, Murday A, Gilbe C, Goldsraw P. Slide tracheoplasty for congenital funnel-shaped tracheal stenosis. Ann Thorac Surg. 1989;48:632-5. 
2. Beierlein W, Elliot M. Variations in the technique of slide tracheoplasty to repair complex forms of long-segment congenital tracheal stenosis. Ann Thorac Surg. 2006;82:1540-2.

3. Kim SM, Han SJ, Choi HS, Nam YT, Oh JT, Choi SH. Slide thyrocricotracheoplasty: a novel technique for congenital laryngeal atresia. Pediatr Surg Int. 2008; 24:383-6. Epub 2007 May 24.
4. Kutlu CA, Yeginsu A, Ozalp T, Baran R. Modified slide tracheoplasty for the management of tracheobronchopathia osteochondroplastica. Eur J Cardiothorac Surg. 2002;21:140-2.

5. Kutlu CA, Goldstraw P. Slide tracheoplasty for congenital funnel shaped tracheal stenosis (a 9-year follow-up of the first case). Eur J Cardiothorac Surg. 1999;16: 98-9.

\title{
A novel technique for bronchopleural fistula closure: An hourglass- shaped stent
}

\author{
Cemal Asim Kutlu, MD, FETCS, Suat Patlakoglu, MD, Ahmet Erdal Tasci, MD, and Oguz Kapicibasi, MD, Istanbul, Turkey
}

Bronchopleural fistula (BPF) occurs in $4.5 \%$ of the patients having pneumonectomy. ${ }^{1}$ It often causes lifethreatening complications that delay the appropriate management of the underlying malignant or infectious disease. Small fistulae tend to close spontaneously with conservative management; however, larger ones usually require reexploration, sometimes necessitating repeated and complex procedures. In recent years, there have been anecdotal reports on the closure of BPFs by stenting. ${ }^{2-4}$ In this article, we describe a novel technique involving the use of an hourglass-shaped tracheobronchial stent for the immediate closure of BPF.

\section{TECHNIQUE AND COMMENT}

In the case of a BPF, urgent drainage of the pleural cavity, together with appropriate antibiotic treatment, prevents the aspiration of infected material into the contralateral lung and is therefore mandatory to achieve infection control at the time of admission. Bronchoscopy should be undertaken at the earliest time possible to evaluate the bronchial stump and the size of the fistula. Management options are decided depending on not only the bronchoscopic findings but also the patient's general condition and underlying disease. We always prefer rigid bronchoscopy under general anesthesia concomitantly with drain revision and/or other drainage techniques, which depend on the further management plan. Removal of infected debris and cleaning of the empyema cavity with daily packing or irrigation are required for the

From the Department of Thoracic Surgery, Sureyyapasa Chest Disease and Chest Surgery Research and Training Hospital, Istanbul, Turkey.

Received for publication Jan 15, 2008; revisions received Feb 22, 2008; accepted for publication March 2, 2008.

Address for reprints: C. A. Kutlu, MD, FETCS, Assistant Professor of Thoracic Surgery, Hakki Yeten Cad, 17/12, Şişli 80200, Istanbul, Turkey (E-mail: cakutlu@tnn. net).

J Thorac Cardiovasc Surg 2009;137:e46-7

$0022-5223 / \$ 36.00$

Copyright (c) 2009 by The American Association for Thoracic Surgery doi:10.1016/j.jtcvs.2008.03.059 local control of infection. However, irrigation, when indicated, carries a risk of aspiration and is poorly tolerated by patients with a large fistula.

Furthermore, depending on the size of the fistula and the patient's preoperative respiratory functions, a BPF may have varying degrees of detrimental effects on respiration. Therefore, early closure of a BPF is essential but challenging in some patients in whom surgical intervention cannot be undertaken. In recent years, there have been anecdotal reports on the use of various types of stents for fistula closure. ${ }^{2-4}$ However, these reported techniques require the localization of the stents in the main airway and are therefore accompanied with increasing risks of potential complications of stenting. ${ }^{5}$

In our technique, which has been undertaken in 3 patients, a covered, distal-release, tracheobronchial stent (Tracheobronxane Silmet; Novetech La Ciotat Cedex, France) was placed in the bronchial stump. The applicability of stenting in a given case was determined during bronchoscopic evaluation; stenting was considered appropriate when the fistula was larger than $5 \mathrm{~mm}$ in diameter, because this diameter was required for the advancement of the introducer through the fistula into the chest cavity. The stent was withdrawn via the previous open-window thoracostomy (Figure 1). The drain incision was widened up to 2 to $3 \mathrm{~cm}$, and the tip of the stent was withdrawn using thoracoscopic guidance in the remaining 2 patients in whom thoracostomy was not planned. The stent was then partially released depending on the length of stump in which the proximal part was to be positioned. Heavy silk suture (No. 0) was tied around the stent to give it an hourglass shape. The stent was withdrawn through the fistula until the proximal unfired part was localized in the proximal part of the stump. Prior to completely releasing the stent, appropriate positioning of the narrowest part of the stent was ensured by checking its position from both the sides under direct vision. It can be speculated that our technique reduces the potential risks accompanying stenting. On the other hand, in patients who require surgical 